\title{
Aggressive primary mediastinal non-Hodgkin's lymphomas: a study of 29 cases
}

\author{
B. Etienne*, P.-H. Guillaud*, R. Loire*, B. Coiffier ${ }^{+}$, F. Berger", J.-F. Cordier*
}

Aggressive primary mediastinal non-Hodgkin's lymphomas: a study of 29 cases. B. Etienne, P.-H. Guillaud, R. Loire, B. Coiffier, F. Berger, J.-F. Cordier. (C)ERS Journals Ltd 1999.

ABSTRACT: Aggressive primary mediastinal non-Hodgkin's lymphomas (NHL) represent a particular entity among intrathoracic neoplasms. Twenty-nine patients with primary mediastinal aggressive NHL diagnosed and treated in the author's institution were studied.

According to the Revised European-American Lymphoma (REAL) classification, there were 15 diffuse large B-cell, eight T-lymphoblastic, four anaplastic, one large Tcell and one Burkitt's lymphomas. The study group consisted of 14 females and 15 males, with a mean age of 38 yrs. Symptoms arose from an aggressive anterior mediastinal mass, with a high prevalence of superior vena caval syndrome, pleural, and pericardial effusions. At the time of diagnosis, disease was confined to supradiaphragmatic areas in $\mathbf{2 4}$ patients, while subdiaphragmatic nodal or extranodal involvement was also present in five.

All patients received a combination of aggressive chemotherapy regimens, mainly according to the French protocols for the treatment of NHL. A chest radiograph response of $<\mathbf{5 0 \%}$ after the first course of chemotherapy and failure to achieve a complete remission after the first line of chemotherapy were significantly associated with unfavourable prognosis. Overall 5-yr and 9-yr survival rates were 55 and $48 \%$, respectively.

Patients properly diagnosed and treated with a combined modality of chemotherapy can experience prolonged survival.

Eur Respir J 1999; 13: 1133-1138.

Unlike patients with Hodgkin's disease who present in two-thirds of cases with initial mediastinal involvement [1], a mediastinal mass is a rare presentation of patients with non-Hodgkin's lymphoma (NHL) [2, 3]. Moreover, mediastinal involvement with paratracheal and mediastinohilar adenopathy is present in $\sim 15-25 \%$ of NHL $[1,3]$ with advanced disease [4]. Primary mediastinal NHL represents only $5-10 \%$ of all aggressive NHL [4]. Twentynine cases of aggressive NHL arising in the mediastinum were retrospectively analysed to ascertain their clinical, radiographic, histopathological, and evolutive features.

\section{Patients and methods}

\section{Selection of patients}

Records of all patients $\geq 15$ yrs of age in whom a diagnosis of aggressive primary mediastinal NHL was made in the author's institution, between 1978 and 1997, were reviewed. Primary NHL was defined as an initial prominent mediastinal mass, with or without contiguous extension to the pleura or lungs, or supraclavicular lymph node involvement $[5,6]$. The presence of extrathoracic involvement was not considered as an exclusion criteria.
*Hôpital Louis Pradel, Lyon, France. ${ }^{+}$Centre Hospitalier Lyon-Sud, Pierre Benite, France. "Hôpital Edouard Herriot, Lyon, France.

Correspondence: J.-F. Cordier

Hôpital Louis Pradel

BP Lyon Montchat

69394 Lyon cedex 03

France

Fax: 33472357653

Keywords: Lymphomas mediastinal lymphomas mediastinal neoplasms

Received: September 151998

Accepted after revision January 211999

\section{Pathology}

Histological specimens were reviewed by two pathologists (R. Loire, F. Berger), confirmed as NHL and subclassified according to the Revised European-American Lymphoma (REAL) classification [7, 8]. Most of them were also reviewed by the French haematopathologists from the Groupe d'Etude des Lymphomes de l'Adulte (GELA). Paraffin sections from all cases were available for immunohistological study.

\section{Clinical presentation}

All clinical symptoms involving both thoracic and extrathoracic manifestations were recorded. Chest radiographs were examined for tumour bulk and pleural effusion. Chest computed tomography (CT) scans were examined for tumour location, presence of necrosis, pulmonary parenchymal involvement, chest wall invasion, and presence of pleural and/or pericardial effusion. The tumour was classified as bulky if the mediastinal diameter on the posteroanterior chest radiograph was $>10 \mathrm{~cm}$.

\section{Staging}

The patients' clinical staging was defined according to the Ann Arbor classification. Staging procedures included 
bone marrow examination, ultrasonography and CT of the abdomen, cardiac ultrasonography, and lumbar puncture. Ann Arbor tumour stage is ambiguous for patients with pleural and/or pericardial effusion. Those patients with contiguous intrathoracic extension were considered as stage IIE, independently of the number of sites involved. NHL International Prognostic Index (IPI) [9] based on: age, tumour staging, serum lactate dehydrogenase (LDH) level, performance status, and number of extranodal involved sites, was defined for each patient.

\section{Therapy}

Therapeutic regimens including conventional aggressive chemotherapy, intensive chemotherapy followed by autologous bone marrow graft, and mediastinal radiation therapy were recorded.

\section{Treatment response}

Treatment response was evaluated by chest radiographs and chest CT scans. Complete remission was defined as the disappearance of all clinical and biological detectable signs of active lymphoma with return to normal of radiographic findings, and partial remission was defined as a $>50 \%$ reduction in tumour area. Patients with residual mediastinal masses with no other evidence of disease were grouped with those in complete remission for the analysis of factors affecting survival. Residual mediastinal abnormalities were thought to be scar tissue from the treatment.

\section{Statistical analysis}

Overall survival duration was calculated from the date of diagnosis to the date of death or last follow-up. Disease free survival duration was calculated from the date of diagnosis to the date of relapse or last follow-up. Survival curves were plotted using the Kaplan-Meier method. Overall survival and disease free survival were evaluated by stratified analysis for age, sex, histological subgroup, presence of pleural effusion, presence of pericardial effusion, LDH level, size of lesions, clinical staging, IPI staging, radiographic response after the first course of chemotherapy, and achievement of complete remission after the first line of chemotherapy. Score test (log-rank test) was used to identify univariate predictors.

\section{Results}

Thirty-eight patients were identified, of whom nine were eliminated from the study for inadequate clinical or followup information in two cases, diagnosis of Hodgkin's disease in three cases, and nonaggressive NHL (follicle centre, follicular according to the REAL classification) in four cases after pathological revision. Among the remaining 29 patients, 22 were diagnosed in the previous $10 \mathrm{yrs}$. Diagnostic tissue samples were obtained by thoracotomy in 18 cases, mediastinoscopy in three cases, superficial cervical lymph node biopsy in seven cases, and one case was diagnosed by bronchial biopsy. The distribution of his-
Table 1. - Distribution of histopathological types in 29 cases of primary mediastinal non-Hodgkin's lymphoma (according the Revised European-American Lymphoma classification)

\begin{tabular}{lr}
\hline Type & $\mathrm{n}(\%)$ \\
\hline Diffuse large B-cell & $15(51)$ \\
T-lymphoblastic & $8(28)$ \\
Anaplastic & $4(14)$ \\
Large T-cell & $1(3.5)$ \\
Burkitt & $1(3.5)$ \\
\hline
\end{tabular}

topathological types in the 29 cases of malignant mediastinal NHL is shown in table 1 . The most common pathological type was diffuse large B-cell lymphoma (15 patients), followed by T-lymphoblastic lymphoma (eight patients). The 29 cases described represented $11.5 \%$ of the 252 primary mediastinal tumours recorded by the author's pathology department over the study period, whereas thymomas made up $42 \%$.

\section{Clinical presentation}

Of the 29 patients, 15 were male and 14 were female. Of the 15 patients presenting with diffuse large B-cell NHL, eight were male and seven were female. Mean age at diagnosis was 38 yrs (range 15-65 yrs), with 17 patients $<40$ yrs of age. Ten patients (34.5\%) had a $\geq 10$ pack-yr history of smoking.

The presenting symptoms and physical findings are presented in table 2 . No patient was asymptomatic. Thoracic symptoms were rapid in onset (mean time between beginning of symptoms and diagnosis: 2.5 months) and sometimes life-threatening: eight patients $(28 \%)$ presented with a progressive superior vena caval syndrome and two $(7 \%)$ with cardiac tamponade syndrome. Extrathoracic symptoms were: asthenia in 14 cases $(48 \%)$, weight loss in nine $(31 \%)$, and fever in eight $(28 \%)$. Six patients $(20 \%)$ presented with an ipsilateral cervical or supraclavicular adenopathy in direct contiguity with the primary tumour.

At chest radiograph, the mediastinal mass was anterior in 19 cases $(65.5 \%)$, anterior and middle in eight cases $(28 \%)$, posterior in one case $(3.5 \%)$, and in another case the three compartments of the mediastinum were involved. Pleural effusion was present at chest radiography in 13 patients (45\%), unilateral in 10 and bilateral in three, and could be moderate (eight cases) or abundant (five cases).

Table 2. - Clinical features and physical findings at presentation in 29 patients with non-Hodgkin's lymphoma

\begin{tabular}{lc}
\hline Symptoms and signs & $\mathrm{n}(\%)$ \\
\hline Cough & $18(62)$ \\
Chest pain & $14(48)$ \\
Superior vena caval syndrome & $8(28)$ \\
Dysphonia & $4(14)$ \\
Haemoptysis & $4(14)$ \\
Tachyarrythmia & $2(7)$ \\
Chest wall invasion & $2(7)$ \\
Asthenia & $14(49)$ \\
Fever & $9(31)$ \\
Weight loss (>10\% body weight) & $8(28)$ \\
\hline
\end{tabular}


Cytological examination of the pleural fluid showed the presence of lymphoma cells in four out of $13(30 \%)$ cases. Pericardial fluid was present in $10(38 \%)$ of the 26 patients who had a CT thoracic scan, and cardiac ultrasonography confirmed pericardial effusion in these cases. An emergency surgical pleuro-pericardial communication had to be made in two cases, neither of which showed the presence of lymphoma cells in the pericardial fluid by cytological examination. CT thoracic scans demonstrated cystic areas in masses suggesting necrosis in nine cases (35\%) (fig. 1), contiguous lung involvement in 11 cases $(42 \%)$, pleural effusions in 13 cases, and contiguous chest wall invasion in two cases $(7 \%)$. Nineteen patients $(65 \%)$ presented with bulky tumour (fig. 2).

Fibreoptic bronchoscopy performed in 20 out of 29 patients showed extrinsic compression in seven, and bronchial inflammation in 13, but histological examination indicated lymphoma in only two out of 13 bronchial biopsies.

\section{Staging}

According to the Ann Arbor classification, 24 patients were classified in clinical stage II or IIE at the time of diagnosis, two in stage III, and three in stage IV. Among the patients with stage IV disease, one presented with initial bone marrow and spinal fluid involvement (T-lymphoblastic NHL), one with bone involvement (Burkitt's NHL), and one with pancreatic involvement confirmed by cytological examination (large B-cell NHL). Three patients had B symptoms (night sweats, unexplained fever $>38^{\circ} \mathrm{C}$, and weight loss ( $>10 \%$ of body weight in $<6$ months)). By the IPI classification, 21 patients were in the low group (0 or 1 risk factor), seven in the low intermediate (2 risk factors), one in the high intermediate (3 risk factors), and one in the high (4 or 5 risk factors).

\section{Results of treatment}

No patient had previously been treated elsewhere. All patients received a combination of aggressive chemotherapy regimens, mainly according to the French protocols for

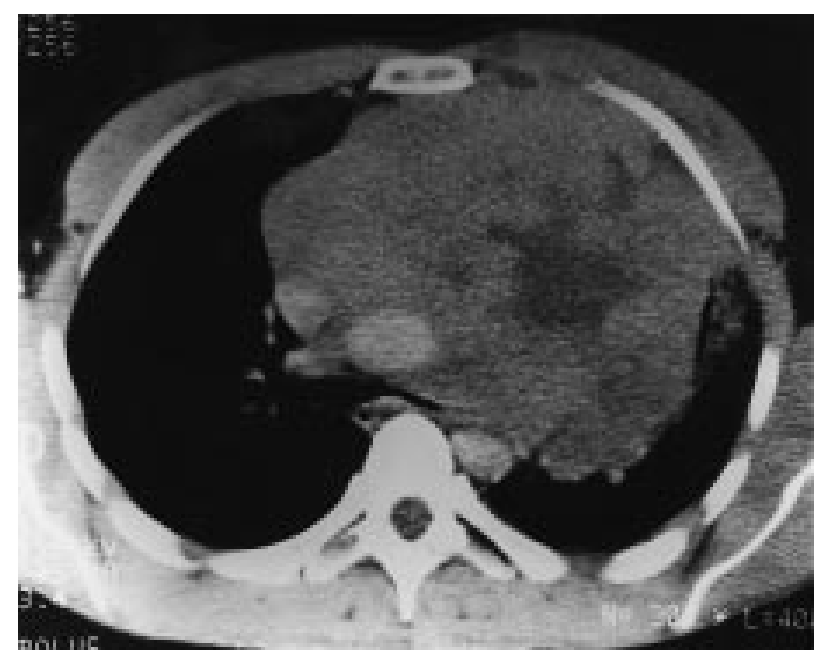

Fig. 1. - Chest computed tomography scan (1 mm slices) showing presence of necrosis in the tumour and chest wall invasion.

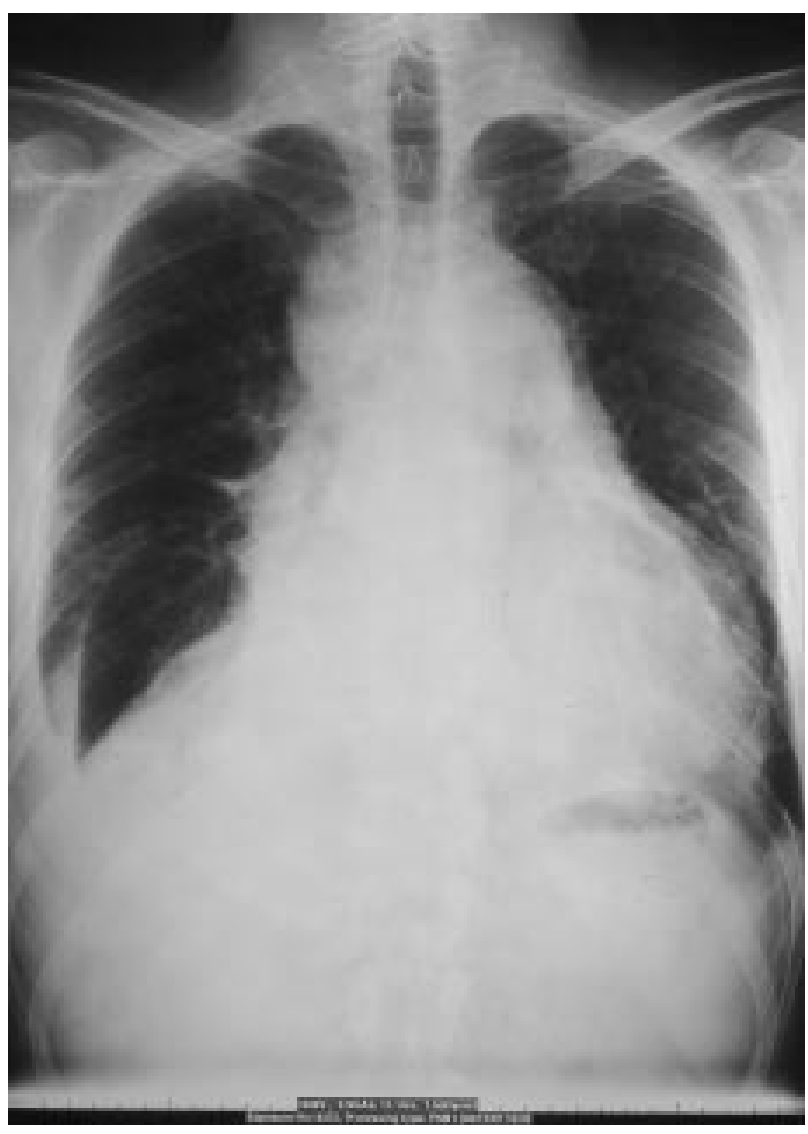

Fig. 2. - Anteroposterior chest radiograph showing a bulky tumour with pericardial effusion and controlateral pleural effusion.

treatment of NHL (lymphomes non-Hodgkiniens (LNH)84, LNH-87, LNH-93) [10], and 18 patients were included in these multicentre studies. Induction chemotherapy consisted of combination doxorubicin-containing regimens: doxorubicin, cyclophosphamide, vindesine, bleomycin, and prednisone (ACVBP); methotrexate with leucovorin, doxorubicine, cyclophosphamide, vincristine, prednisone, and bleomycin (MACOP-B); cyclophosphamide, doxorubicin, vincristine, and prednisone (CHOP); and ifosfamide, methotrexate and prednisone (VIM), were usually used. Thirteen patients (eight in first complete remission and five in second complete remission) further received an intensive chemotherapy followed by autologous bone marrow transplantation in the bone marrow transplant unit at the Centre Hospitalier Lyon Sud (eight patients) or the Centre Leon Berard (five patients) (table 3). Ten patients (two in first remission and eight in local relapse) received mediastinal radiotherapy. With a median follow-up of 70 months (range $1-112$ months), 15 patients are alive: 14 without any evidence of disease and one with progressive disease. Three of 29 patients were immediately refractory to chemotherapy and died from NHL, whereas remission after the first line of chemotherapy was obtained in the 26 remaining patients (20 complete remission, and six partial remission).

Nineteen patients had a residual mediastinal mass which was evaluated by pathological restaging in only two cases. Initial relapses with a median delay of 6 months (range 148 months) were seen in 16 out of 26 cases (14 in complete 
Table 3. - Baseline characteristics, treatment, response and ultimate outcome for patients treated with intensive chemotherapy followed by autologous bone marrow transplantation (BMT)

\begin{tabular}{|c|c|c|c|c|c|c|c|}
\hline $\begin{array}{l}\text { Patient } \\
\text { No. }\end{array}$ & $\begin{array}{l}\text { Sex } \\
(\mathrm{M}, \mathrm{F})\end{array}$ & $\begin{array}{l}\text { Age } \\
\text { yrs }\end{array}$ & $\begin{array}{l}\text { Ann Arbor } \\
\text { stage }\end{array}$ & REAL type & $\begin{array}{c}\text { Clinical status before } \\
\text { BMT }\end{array}$ & Treatment & Outcome \\
\hline 1 & M & 30 & II & LBC & CR1 & BEAM & Alive \\
\hline 2 & $\mathrm{~F}$ & 26 & II & LBC & CR1 & BEAM & Alive \\
\hline 3 & M & 37 & II & LBC & CR1 & CPM/VP16 & Alive \\
\hline 4 & $\mathrm{M}$ & 16 & II & Anaplastic & CR1 & ISA & Alive \\
\hline 5 & $\mathrm{~F}$ & 39 & II & Anaplastic & CR1 & BEAM & Alive \\
\hline 6 & $\mathrm{~F}$ & 18 & II & Lymphoblastic & CR1 & CPM/TBI & Died \\
\hline 7 & $\mathrm{M}$ & 26 & II & Lymphoblastic & CR1 & BEAM & Alive \\
\hline 8 & M & 42 & IV & Lymphoblastic & CR1 & CPM/VP16 & Died \\
\hline 9 & $\mathrm{~F}$ & 48 & IV & LBC & CR2 & BEAM & Died \\
\hline 10 & M & 41 & II & Anaplastic & CR2 & BEAM & Alive \\
\hline 11 & $\mathrm{~F}$ & 16 & II & Lymphoblastic & CR2 & $\mathrm{CPM} / \mathrm{TBI}$ & Died \\
\hline 12 & $\mathrm{~F}$ & 20 & II & Lymphoblastic & CR2 & CPM/TBI & Died \\
\hline 13 & M & 31 & IV & Burkitt & CR2 & BEAM & Died \\
\hline
\end{tabular}

M: Male; F: Female; REAL: Revised European-American Lymphoma; LBC: Large B-cell; CR1: first complete remission; CR2: second complete remission; BEAM: 1, 3-bis-(2-chloroethyl)-1-nitrosourea (carmustine), etoposide, cytarabine, melphalan; ISA: cyclophosphamide, etoposide, carmustine; CPM/TBI: cyclophosphamide, total body irradiation; CPM/VP16: cyclophosphamide, etoposide.

remission and two in partial remission): eight were intrathoracic, five extrathoracic, and both intra- and extrathoracic in three cases. Extrathoracic sites of relapse were lymph nodes (three patients), cerebrospinal fluid (two patients), bone marrow (two patients), bone (one patient), and liver (one patient). NHL caused the death of 11 of 16 patients (six from intrathoracic progression, three from extrathoracic, and two from intra- and extrathoracic progression). Of the 19 patients with a residual mediastinal mass, 14 are still alive, while five progressed despite chemotherapy (four died from disease, whereas one is still alive after autologous bone marrow transplantation). Among the five patients treated with intensive chemotherapy after a second remission, one is still alive and four died from disease. Three of eight patients who received thoracic radiotherapy for local relapse are still alive, and five died, all from disseminated disease.

The overall survival rates were $63 \%$ at 3 yrs, $55 \%$ at 5 yrs, and $48 \%$ at 9 yrs (fig. 3). The 5-yr survival without progression was $29 \%$. Age, sex, histopathological subtype, IPI stage, and presence of pericardial effusion influenced neither overall survival nor survival without progression, but these were significantly negatively influenced by absence of complete remission after the first

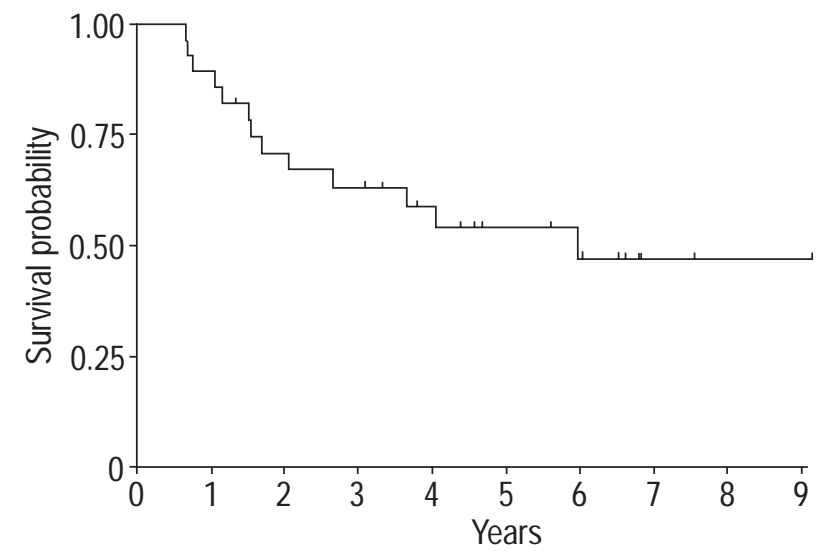

Fig. 3. - Survival plots (Kaplan-Meier) for overall survival for the 29 patients with mediastinal non-Hodgkin's lymphoma. line of chemotherapy and a chest radiograph response of $<50 \%$ after the first course of chemotherapy. A trend toward unfavourable prognosis was associated with high LDH and bulky tumour (table 4).

\section{Discussion}

This study reports on a series of patients with aggressive primary mediastinal NHL diagnosed and followed in a single centre. In agreement with the literature, these aggressive NHL represented only $11.5 \%$ of all mediastinal tumours recorded in the author's institute whereas thymic tumours comprised $\sim 40 \%[11,12]$. Primary aggressive NHL may simulate several mediastinal tumours including advanced thymoma, germ cell tumour, or small cell lung carcinoma with extensive lymphadenopathy.

The primary mediastinal malignant NHLs were categorized by VAN HEERDEN et al. [13] in 1969 and by BENJAMIN et al. [14] in 1972. LiCHTENSTEIN et al. [4] reported a series of 17 patients with primary mediastinal NHL including nine patients with lymphoblastic lymphoma. Lymphoblastic lymphomas were described in the early 1970s, as a subtype of aggressive and high-grade lymphoma seen primarily in young males and having a greater tendency to dissemination, particularly in the meninges and the bone marrow. Lymphoblastic NHL also shares many clinical features with acute lymphoblastic leukaemia associated with a mediastinal mass, and these two entities are

Table 4. - Prognostic factors for survival

\begin{tabular}{lc}
\hline Variable & Survival p-value \\
\hline $\begin{array}{l}\text { Complete remission after first line } \\
\text { of chemotherapy (favourable) }\end{array}$ & 0.0001 \\
Radiographic response $\geq 50 \%$ & 0.02 \\
after the first course of chemotherapy & \\
(favourable) & 0.06 \\
LDH above 350 U.L ${ }^{-1}$ (unfavourable) & 0.1 \\
Tumour bulk (unfavourable) & 0.3 \\
Ann Arbor stage >II (unfavourable) & 0.3 \\
Pleural effusion (unfavourable) &
\end{tabular}

LDH: lactate dehydrogenase. 
thought to represent different phases of the same malignancy [2]. TRUMP and MANN [15] reported a series of 11 adults presenting with nonlymphoblastic primary mediastinal NHL. Using a modified Rappaport classification, 10 cases were classified as diffuse large cell lymphoma and exhibited homogeneous clinical features. Subsequent series, restricting analysis to diffuse large cell lymphoma, identified a characteristic clinical entity usually seen in young females and thought to originate from a specific population of B-cells resident in the thymus [16-19]. However, primary mediastinal lymphomas comprise several distinct histopathological entities. A predominance of large B-cell lymphoma (51\%) was found in this study, but other histological subtypes were also present, especially T-lymphoblastic which represented $28 \%$ of the cases. The current study indicates that, even if histopathological subgroups differ, primary mediastinal NHL have some characteristic clinical features in common. They usually present with thoracic symptoms, which are rapid in onset. Superior vena caval syndrome, pleural and/or pericardial effusion, when associated with mediastinal tumour, should alert to the possibility of a mediastinal NHL (mediastinal NHL account for 5-15\% of superior vena caval syndrome) $[20,21]$. In these patients, there was an equal distribution between the sexes, even among the large Bcell NHL group, unlike the studies of TODESCHINI et al. [22] and LAZZARINO et al. [23] who reported a predominance of females. Although the age at onset was slightly older in this as compared with other series of mediastinal NHL in adults, these occurred in people $<40$ yrs of age in 17 of 29 cases.

NHL in this and other series are bulky anterior mediastinal masses with average diameters of $\geq 10 \mathrm{~cm}$ in twothirds of patients [24]. It is felt that a CT scan of the thorax and the abdomen is crucial because enlarging masses often invade contiguous thoracic structures (pleura, pericardium, vessels, chest wall), and it allows determination of both tumour bulk [22] and its local spread [24]. Although fibreoptic bronchoscopy is often performed in patients with respiratory symptoms, biopsies only rarely provide a diagnosis. The involvement of superficial lymph nodes and extrathoracic spread at presentation are rather infrequent $[4,19,22,25]$, thus leading to aggressive diagnostic surgical procedures such as mediastinoscopy or thoracotomy.

NHL characterized by a very aggressive course must be treated with intensive polychemotherapy: a four- or fivedrug combination regimen (including anthracyclins and steroids) should be given at high dosages and delivered over a short period of time with short intervals between cycles. The present results compare favourably with the literature, with complete remission obtained in $69 \%$ of patients, and an overall 5-yr survival of 55\% [24]. Although previous series had described primary mediastinal NHL as an aggressive disorder with a poor prognosis $[16,26-$ $28]$, more recent studies, especially those of mediastinal large B-cell NHL, have reported more encouraging results of treatment $[19,27]$. Moreover, CAZALs-HATEM et al. [5] did not find any difference between the 3-yr survival of patients with aggressive mediastinal NHL and aggressive nodal NHL. KIRN et al. [25] noted the presence of pleural effusion as a poor prognostic factor with $88 \%$ of patients relapsing in the presence of pleural effusion on CT scan versus $42 \%$ for those without effusions.
LAZZARINO et al. [23] found that poor performance status and pericardial effusion were the two main independent factors associated with risk of death. Bulky tumour [29], persistence of a residual mass [5], and absence of chemosensitivity $[14,25]$ were also reported as unfavourable prognostic signs. In this series, prognosis was poorer when the first line of chemotherapy failed to achieve a complete remission, and when radiographic response after the first course of chemotherapy was $<50 \%$. Patients with high-grade NHL responding rapidly to therapy with achievement of complete remission after two months of chemotherapy, have a better prognosis than those achieving complete remission more slowly [24, 30, 31]. A radiographic response to the first course of chemotherapy of $<50 \%$ should be considered as a warning sign for nonresponse to standard therapy. Response to early doseintensive salvage therapy is possible and may benefit patients with partial remission [30]. It is felt that intensive chemotherapy followed by autologous bone marrow transplantation should be considered for patients with a chest radiograph response of $<50 \%$ after the first course of chemotherapy, or failure to achieve a complete remission after the first line of chemotherapy, or resistance to standard chemotherapy.

Patients with aggressive NHL often have residual masses on early restaging studies [32]. These may regress or resolve on follow-up CT scans [25, 29], but increased frequency of relapses and deaths has also been reported [5]. For such residual masses, three main options may be considered: further treatment (possibly involving excessive and perhaps unnecessary therapy), pathological analysis where a needle biopsy may not be sufficient, thus making surgery necessary, or observation [32]. Early restaging by a gallium scan may identify patients with poor prognosis, i.e. those whose tumours remain gallium avid after two cycles of chemotherapy [33]. In such cases, and when the initial tumour was bulky, involved-field radiotherapy may be indicated. Nevertheless in this series, whereas initial relapses more frequently involved the intrathoracic compartment, only a few patients died from local evolution. Consequently, the authors, like others, consider that radiotherapy is still controversial $[18,21]$.

In conclusion, primary mediastinal aggressive nonHodgkin's lymphoma represents a distinct and characteristic entity among intrathoracic neoplasms. These are characterized pathologically by a predominance of diffuse large B-cell and lymphoblastic T-lymphomas. Despite different histological subtypes, they share some characteristic clinical, radiographic and evolutive features. Presenting symptoms of these tumours are usually thoracic, such as rapid in onset superior vena caval syndrome, reflecting bulky, invasive masses that may invade adjacent structures. Aggressive surgical procedures such as thoracotomy or mediastinoscopy are often necessary to obtain a precise pathological diagnosis. The therapeutic approach should be adapted to the histological subtype and requires chemotherapy regimens delivered at full dosages as for aggressive NHL. An absence of complete remission after the first line of chemotherapy and a chest radiograph response after the first course of chemotherapy of $<50 \%$ were found to be unfavourable prognostic factors. Patients properly diagnosed and treated with a combined modality of chemotherapy can experience prolonged survival. 
Acknowledgements. The authors are grateful to C. Sebban, Centre Leon Berard, for help in the statistical analysis of the data and to T. Greenland for critically reviewing this manuscript.

\section{References}

1. Filly R, Blanck N, Castellino RA. Radiographic distribution of intrathoracic disease in previously untreated patients with Hodgkin's disease and non-Hodgkin's lymphoma. Radiology 1976; 120: 277-281.

2. Strollo DC, Rosado-de-Christenson ML, Jett JR. Primary mediastinal tumors. Part II. Tumors of the middle and posterior mediastinum. Chest 1997; 112: 1344-1357.

3. Jones SE, Fuks Z, Bull M, et al. Non-Hodgkin's lymphomas. Clinicopathologic correlation in 405 cases. Cancer 1973; 4: 806-823.

4. Lichtenstein AK, Levine A, Taylor CR, et al. Primary mediastinal lymphoma in adults. Am J Med 1980; 68: 509-514.

5. Cazals-Hatem D, Lepage E, Brice P, et al. Primary mediastinal large B cell lymphoma. Am J Surg Pathol 1996; 20: $877-888$.

6. Levitt LJ, Aisenberg AC, Harris NL, Linggood RM, Poppema S. Primary non-Hodgkin's lymphoma of the mediastinum. Cancer 1982; 50: 2486-2492.

7. Harris NL, Jaffe ES, Stein H, et al. A Revised EuropeAmerican Classification of lymphoid neoplasms: a proposal from the international lymphoma study group. Blood 1994; 84: 1361-1392.

8. Hiddeman W, Longo DL, Coiffier B, et al. Lymphoma classification - the gap between biology and clinical management is closing. Blood 1996; 88: 4085-4089.

9. Shipp M, Harrington D, Anderson J. A predictive model for aggressive non-Hodgkin's lymphoma. $N$ Engl J Med 1993; 329: 987-994.

10. Coiffier B, Gisselbrecht C, Herbrecht R, Tilly H, Bosly A, Brousse N. LNH84-regimen: a multicentric study of intensive chemotherapy in 737 patients with aggressive malignant lymphomas. J Clin Oncol 1989; 7: 1018-1026.

11. Walsh GL. General principles and surgical considerations in the management of mediastinal masses. In: Roth JA, Ruckdeschel JC, Weisenburger TH, eds. Thoracic Oncology. Philadelphia, WB Saunders, 1995; pp. 445-467.

12. Cohen AJ, Thompson LN, Edwards FH, Bellamy RF. Primary cysts and tumors of the mediastinum. Ann Thorac Surg 1991; 51: 378-386.

13. Van Heerden JA, Harrison EG, Bernatz PE, Kiely JM. Mediastinal malignant lymphoma. Chest 1969; 57: 518529.

14. Benjamin SP, McCormack J, Effler DB, Groves LK. Primary lymphatic tumors of the mediastinum. Cancer 1972; 3: 708-712.

15. Trump DL, Mann RB. Diffuse large cell and undifferentiated lymphomas with prominent mediastinal involvement. Cancer 1982; 50: 277-282.

16. Perrone T, Frizzera G, Rosai J. Mediastinal diffuse large cell lymphoma with sclerosis. A clinicopathologic study of 60 cases. Am J Surg Pathol 1986; 10: 176-191.

17. Yousem SA, Weiss LM, Warnke RA. Primary mediastinal non-Hodgkin's lymphoma: morphologic and immuno- logic study of 19 cases. Am J Clin Path 1985; 83: 676680.

18. Al-Sharabati M, Chittal S, Duga-Neulat I, et al. Primary anterior mediastinal B-cell lymphoma. A clinicopathologic and immunohistochemical study of 16 cases. Cancer 1991; 67: 2579-2587.

19. Lamarre L, Jacobson JO, Aisenberg AC, Harris UL. Primary large cell lymphoma of the mediastinum. A histologic and immunophenotypic study of 29 cases. Am J Surg Pathol 1989; 13: 730-739.

20. Yellin A, Rosen A, Reichert N, Lieberman Y. Superior vena cava syndrome. The myth, the facts. Am Rev Respir Dis 1990; 141: 1114-1118.

21. Hoffman OA, Gillespie DJ, Aughenbaugh GL, Brown LR. Primary mediastinal neoplasms (other than thymoma). Mayo Clin Proc 1993; 68: 880-891.

22. Todeschini G, Ambrosette A, Moneghini V, et al. Mediastinal large B-cell lymphoma with sclerosis. A clinical study of 21 patients. J Clin Oncol 1990; 8: 804-808.

23. Lazzarino M, Orlandi E, Paulli $\mathrm{M}$, et al. Treatment outcome and prognostic factors for primary mediastinal (thymic) B-cell lymphoma. A multicenter study of 106 patients. J Clin Oncol 1997; 15: 1646-1653.

24. Shaffer K, Smith D, Kirn D, et al. Primary mediastinal large B-cell lymphoma. Radiologic findings at presentation. Am J Roentgenol 1996; 167: 425-430.

25. Kirn D, Mauch P, Shaffer K, et al. Large cell and immunoblastic lymphoma of the mediastinum: prognostic features and treatment outcome in 57 patients. J Clin Oncol 1993; 11: 1336-1343.

26. Haioun C, Gaulard P, Roudot-hovaral F, et al. Mediastinal diffuse large cell lymphoma with sclerosis. A condition with a poor prognosis. Am J Clin Oncol 1989; 12: 425429.

27. Aisenberg AC. Primary large-cell lymphoma of the mediastinum. J Clin Oncol 1993; 11: 2291-2294.

28. Lavabre-Bertrand T, Donadio D, Fegueux N, et al. A study of 15 cases of primary mediastinal lymphoma of Bcell type. Cancer 1992; 69: 2561-2566.

29. Jacobson JO, Aisenberg AC, Lamarre L, et al. Mediastinal large cell lymphoma. An uncommon subset of adult lymphoma curable with combined modality therapy. Cancer 1988; 62: 1893-1898.

30. Haq R, Franssen SE, Berinstein NL. Significance of a partial or slow response to front-line chemotherapy in the management of intermediate-grade or high-grade nonHodgkin's lymphoma. A literature review. J Clin Oncol 1994; 12: 1074-1084.

31. Armitage JO, Weisenburger DD, Hutchins M, et al. Chemotherapy for diffuse large-cell lymphoma. Rapidly responding patients have more durable remissions. J Clin Oncol 1986; 4: 160-164.

32. Uematsu M, Kondo M, Tsutsui $\mathrm{T}$, et al. Residual masses on follow-up computed tomography in patients with mediastinal non Hodgkin's lymphoma. Clin Radiol 1989; 40: 244-247.

33. Janicek M, Kaplan W, Neuberg D, Canellos GP, Shulman LN, Shipp MA. Early restaging gallium scans predict outcome in poor-prognosis patients with agressive nonHodgkin's lymphoma treated with high-dose CHOP chemotherapy. J Clin Oncol 1997; 15: 1631-1637. 